\title{
GENETIC LINKAGE BETWEEN OVALOCYTOSIS AND THE RH BLOOD TYPE ${ }^{1}$
}

\author{
By RICHARD A. MARSHALL, ROBERT M. BIRD, H. K. BAILEY, AND \\ ESTHER BECKNER \\ (From the Department of Medicine, University of Oklahoma School of Medicine, \\ Oklahoma City, Okla.)
}

(Submitted for publication December 7, 1953; accepted January 20, 1954)

The presence of elliptical or oval erythrocytes in peripheral blood has been noted in various racial groups since its first accurate description by Dresbach (1) in 1904. Hunter and Adams (2) showed that ovalocytosis was inherited, and Cheney (3) established the pattern of inheritance as that of a simple autosomal Mendelian dominant. Early interest in this anomaly centered around the possibility that the trait might serve as an explanation for a hemolytic anemia. Recently, interest in genetic linkage relationships of such hereditary erythrocytic traits has arisen. Information as to genetic linkage may provide a method of predicting the occurrence of hereditary diseases.

In the summer of 1952 , when a patient with ovalocytosis came to our attention, a study of her entire family was undertaken in an attempt to demonstrate a clear-cut case of linkage in this dominant trait. We proposed two questions: 1 . Is there any linkage between the genes for ovalocytosis and those which determine the antigens in the various blood groups? 2. Do the numbers of oval erythrocytes have any bearing on the occurrence of a hemolytic anemia?

\section{CASE MATERIALS AND METHODS}

Figure 1 is the pedigree of the Family R. Twentyeight members of this family and three spouses were studied. Dried blood films were prepared from venous or shed blood to demonstrate the presence or absence of ovalocytes and their approximate number in those af fected. Slides were read independently by at least two of the authors. Reticulocytes were counted in dry blood films. Hematocrit and serum bilirubin were determined according to techniques used by Wintrobe (4) with heparin as the anti-coagulant. Affected members were compared with their normal siblings.

\footnotetext{
1 Preliminary report was presented in part in Federation Proceedings, 12 : 16, March, 1953; final report given before Midwestern Section, American Federation for Clinical Research, October 29, 1953.
}

The marker genes chosen for the linkage study are those which determine the blood group antigens for the ABO, MNs, Rh, Lewis, Kell, and Duffy systems. The genetic basis of these groups is well established and they can be accurately and readily determined. Saline cell suspensions were prepared from clotted blood in determining these blood groups using the test tube method. Complete serial typing was done on the 22 family members and the three spouses.

\section{RESULTS}

The data pertaining to ovalocytosis and to the blood types are tabulated in Appendix A. In twelve of 26 members of this family, 15 to 85 per cent of the erythrocytes were oval. Of the total family, only 18 individuals have affected parents, and only one, the proposita (III-6), showed any significant degree of reticulocytosis. The osmotic fragility and fecal urobilinogen on this patient were normal. When the indirect reacting serum bilirubin, the reticulocyte counts, and hematocrit determinations on persons affected with ovalocytosis were compared with their unaffected controls, there were no differences which are statistically significant in the small number of instances. These data are presented in Appendix B. Here, the percentage of oval cells expresses the average of multiple determinations. In the other column, where more than one test was run, the lowest hematocrit is recorded, the highest reticulocyte count and the most abnormal van den Berg. There was no past history of hemolytic anemia in any of these individuals.

The results of the blood typing data on the $\mathrm{ABO}$, MNs, Lewis, Kell, and Duffy systems agree with other investigators (5-7) in that there is no indication of close linkage between the genes of these systems and the gene for ovalocytosis. Inspection of Figure 1 reveals that in each of the eleven individuals on whom complete data were obtained, the chromosomal distribution for the oval traits 


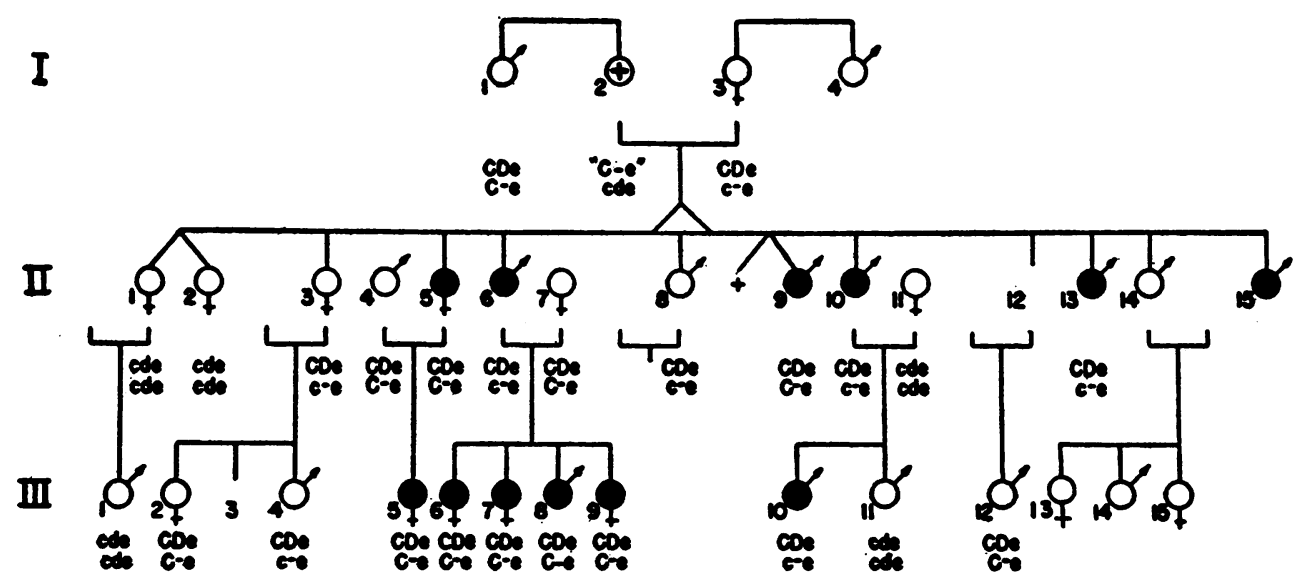

\section{PEDIGREE of FAMILY " $R$ " \\ - OVALOCYTOSIS \\ O- NORMAL ERYTHROCYTES \\ +- DECEASED}

Fig. 1

and the $R h$ pattern $C D e\left(R_{1}\right)$ are identical. This indicates genetic linkage. Of the unaffected members with affected parents, only two, II-3 and II-8, have this $\mathrm{Rh}$ pattern.

\section{DISCUSSION}

From these limited data we conclude that an increased proportion of elliptical erythrocytes in the peripheral blood is not accompanied by an increased tendency toward hemolysis in this family during the period studied. These data do not exclude the possibility of an episodic type of hemolytic anemia, nor do the number of examinations performed warrant a categorical opinion. It is possible that in ovalocytosis the expression of a clinically discernible anemia is dependent upon homozygosity as was found by Valentine and Neel $(8,9)$ for thalassemia major and minor. In order to test this hypothesis in ovalocytosis, it would be necessary to find homozygous persons. In view of the limited incidence of ovalocytosis as indicated by the studies of Wyandt, Bancroft, and Winship (10), this question will be difficult to resolve.

In examining the pedigree of Family $R$ (Figure 1), two members, i.e., II-3 and II-8, who do not show the oval trait, have the chromosome represented by $\operatorname{CDe}\left(R_{1}\right)$ which was common to all in- dividuals with ovalocytosis. These two members have affected parents, thus separating them from the remaining three normal persons showing the $\mathrm{CDe}$ representation. Such an occurrence can be explained by assuming that II-3 and II-8 inherited the CDe complex from the parent who did not exhibit ovalocytosis. Another possibility is that these two people represent cross-overs. Our study on linkage confirms the report of Goodall, Hendry, Lawler, and Stephen (6) of an independent, simultaneous investigation. Since the data of these English workers are more conclusive than those presented in this paper, we feel justified in concluding that in some families the gene for ovalocytosis is definitely on the same chromosome as are the genes for the Rh blood groups, and that the linkage is unusually close. In two other families reported by Chalmers and Lawler (5) the establishment of linkage between ovalocytes and the $\mathrm{Rh}$ blood group is equivocal. Such observations illustrate the lack of homogeneity in human linkage studies.

Although ovalocytosis in most cases is not a disease state, the establishment of a clear-cut case of linkage in an hereditary, human trait provides a new tool for clinical investigation. This will perhaps provide the method necessary to evaluate the role of genetic predisposition to such familial 
diseases as certain types of idiopathic epilepsy and diabetes mellitus. To date the relative importance of heredity and environment in producing these diseases has not been properly evaluated. Identical twin studies have been the best method yet proposed, but these are limited by the rarity of identical wins raised in different environments. Close linkage with an easily determined genetic trait such as blood groups would allow one to evaluate the relative importance of genetic and environmental influences by comparing the results of the genetic type with the manifestation of the disease.

\section{SUMMARY AND CONCLUSIONS}

1. A large family in which ovalocytosis occurred as a dominant trait has been catalogued as to the blood type of the individual members. Evidence for a hemolytic anemia in affected members was sought, but not found.

2. On the basis of the data reported, it is postulated that the gene for ovalocytosis is on the same chromosome as are the genes for the $\mathrm{Rh}$ blood groups.

\section{ACKNOWLEDGMENTS}

We wish to thank Drs. Paul R. David and Lawrence H. Snyder for their advice and criticism, and Mr. Glen $\mathbf{H}$. Hill of Ortho Research Foundation who kiridly supplied some of the typing sera used.

\section{REFERENCES}

1. Dresbach, M., Elliptical human red corpuscles. Science, 1904, 19, 469.

2. Hunter, W. C., and Adams, R. B., Hematologic study of three generations of a white family showing elliptical erythrocytes. Ann. Int. Med., 1929, 2, 1162.

3. Cheney, G., Elliptic human erythrocytes. J.A.M.A., 1932, 98, 878.

4. Wintrobe, M. M., Clinical Hematology, ed. 3, Philadelphia, Lea and Febiger, 1951.

5. Chalmers, J. N. M., and Lawler, S. D., Data on linkage in man; elliptocytosis and blood groups. I. Families 1 and 2. Ann. Eugenics, 1953, 17, 267.

6. Goodall, H. B., Hendry, D. W. W., Lawler, S. D., and Stephen, S. A., Data on linkage in man; elliptocytosis and blood groups. II. Family 3 . Ann. Eugenics, 1953, 17, 272.

7. Burks, B., and Wyandt, H., Oval blood cells in human subjects tested for linkage with taste for P.T.C., mid-digital hair, hair colour, A-B agglutinogens, and sex. Genetics, 1941, 26, 223.

8. Valentine, W. N., and Neel, J. V., Hematologic and genetic study of the transmission of thalassemia. Arch. Int. Med., 1948, 74, 185.

9. Valentine, W. N., and Neel, J. V., A statistical study of the hematologic variables in subjetts with thalassemia minor. Am. J. M. Sc., 1948; 215, 456.

10. Wyandt, H., Bancroft, P., and Winship, T., Elliptic erythrocytes in man. Arch. Int. Med., 1941, 68, 1043. 
GENETIC LINKAGE OF OVALOCYTES AND RH BLOOD TYPE

APPENDIX A-FAMILY " $R$ "

\begin{tabular}{|c|c|c|c|c|c|c|c|c|c|}
\hline \multicolumn{2}{|c|}{$\begin{array}{c}\text { Generation } \\
\text { and } \\
\text { number }\end{array}$} & \multirow{2}{*}{$\begin{array}{c}\begin{array}{c}\text { Age, } \\
\text { years }\end{array} \\
70 \\
\mathbf{6 8} \\
70\end{array}$} & \multirow{2}{*}{$\begin{array}{c}\begin{array}{c}\text { Average } \\
\% \\
\text { ovalocytes }\end{array} \\
0 \\
0 \\
0\end{array}$} & \multirow{2}{*}{$\begin{array}{l}\text { ABO } \\
\mathbf{0} \\
\text { A1 } \\
\ldots\end{array}$} & \multirow{2}{*}{$\begin{array}{c}\text { Rhesus } \\
\text { CCD.ee } \\
\text { CcD.ee }\end{array}$} & \multirow{2}{*}{$\begin{array}{l}\text { MNS } \\
\text { NS } \\
\text { Ns }\end{array}$} & \multirow{2}{*}{$\begin{array}{c}\begin{array}{c}\text { Lewis } \\
\text { Les }^{*}\end{array} \\
- \\
\overline{.}\end{array}$} & \multirow{2}{*}{$\begin{array}{c}\text { Kell } \\
- \\
\ldots\end{array}$} & \multirow{2}{*}{\begin{tabular}{c}
$\begin{array}{c}\text { Duffy } \\
\text { Fy }\end{array}$ \\
$\because$ \\
\hdashline \\
$\cdots$
\end{tabular}} \\
\hline I & $\begin{array}{l}1 \\
3 \\
4\end{array}$ & & & & & & & & \\
\hline II & $\begin{array}{r}1 \\
2 \\
3 \\
4 \\
5 \\
6 \\
7 \\
8 \\
9 \\
10 \\
11 \\
13 \\
14 \\
15\end{array}$ & $\begin{array}{l}47 \\
47 \\
45 \\
40(?) \\
38 \\
39 \\
38 \\
33 \\
32 \\
30 \\
28 \\
28 \\
30 \\
19\end{array}$ & $\begin{array}{r}0 \\
0 \\
0 \\
0 \\
21 \\
33 \\
0 \\
0 \\
15 \\
85 \\
0 \\
25 \\
0 \\
35\end{array}$ & $\begin{array}{l}\mathbf{0} \\
0 \\
0 \\
0 \\
0 \\
\text { A1 } \\
\text { A1 } \\
0 \\
\text { A1 } \\
0 \\
\text { B } \\
\text { A1 } \\
\cdots \\
\cdots\end{array}$ & $\begin{array}{c}\text { ccddee } \\
\text { ccddee } \\
\text { CcD.ee } \\
\text { CCD.ee } \\
\text { CCD.ee } \\
\text { CcD.ee } \\
\text { CCD.ee } \\
\text { CcD.ee } \\
\text { CCD.ee } \\
\text { CcD.ee } \\
\text { ccddee } \\
\text { CcD.ee } \\
. . \\
. .\end{array}$ & $\begin{array}{l}\text { NS(?) } \\
\text { Ns } \\
\text { Ns } \\
\text { MNS } \\
\text { NS } \\
\text { NS } \\
\text { Ns } \\
\text { Ns } \\
\text { NS } \\
\text { NS } \\
\text { NS } \\
\text { NS } \\
. . \\
. .\end{array}$ & $\begin{array}{l}\overline{-} \\
\overline{+} \\
\pm \\
\bar{z} \\
\overline{-} \\
= \\
\overline{-} \\
\therefore\end{array}$ & $\begin{array}{l}\bar{z} \\
\bar{z} \\
\underline{z} \\
\bar{z} \\
\bar{z} \\
\bar{z} \\
\cdots \\
\therefore\end{array}$ & $\begin{array}{l}- \\
z \\
z \\
\ddot{z} \\
z \\
\ddot{z} \\
z \\
\therefore \\
\therefore\end{array}$ \\
\hline III & $\begin{array}{r}1 \\
2 \\
4 \\
5 \\
* 6 \\
7 \\
8 \\
9 \\
10 \\
11 \\
12 \\
13 \\
14 \\
15\end{array}$ & $\begin{array}{r}23 \\
24 \\
20 \\
15 \\
16 \\
13 \\
9 \\
6 \\
12 \\
9 \\
9 \\
4 \\
3 \\
2\end{array}$ & $\begin{array}{r}0 \\
0 \\
0 \\
41 \\
30 \\
15 \\
18 \\
48 \\
47 \\
0 \\
0 \\
0 \\
0 \\
0\end{array}$ & $\begin{array}{l}0 \\
\text { B } \\
\text { B } \\
0 \\
\text { A1 } \\
\text { A1 } \\
\text { A1 } \\
\text { A1 } \\
0 \\
0 \\
0 \\
\ddot{A} 2 \\
\text { A2 }\end{array}$ & $\begin{array}{c}\text { ccddee } \\
\text { CCD.ee } \\
\text { CcD.ee } \\
\text { CCD.ee } \\
\text { CCD.ee } \\
\text { CCD.ee } \\
\text { CCD.ee } \\
\text { CCD.ee } \\
\text { CcD.ee } \\
\text { ccddee } \\
\text { CCD.ee } \\
\ldots \\
. . \\
. .\end{array}$ & $\begin{array}{l}\text { MNS } \\
\text { NS } \\
\text { MNS } \\
\text { MNS } \\
\text { NS } \\
\text { NS } \\
\text { NS } \\
\text { NS(?) } \\
\text { NS } \\
\text { NS } \\
\text { MNs } \\
\ddot{M N} . \\
\text { MN. }\end{array}$ & $\begin{array}{l}\bar{z} \\
\bar{z} \\
\overline{-} \\
\bar{z} \\
\overline{-} \\
\overline{-} \\
\overline{ } \\
\therefore \\
\therefore\end{array}$ & $\begin{array}{l}z \\
= \\
= \\
= \\
= \\
= \\
= \\
\therefore \\
\therefore\end{array}$ & $\begin{array}{l}\bar{z} \\
\bar{z} \\
\underline{z} \\
z \\
z \\
z \\
z \\
\therefore \\
\therefore\end{array}$ \\
\hline
\end{tabular}

* Proposita.

APPENDIX B-FAMILY " $R$ "

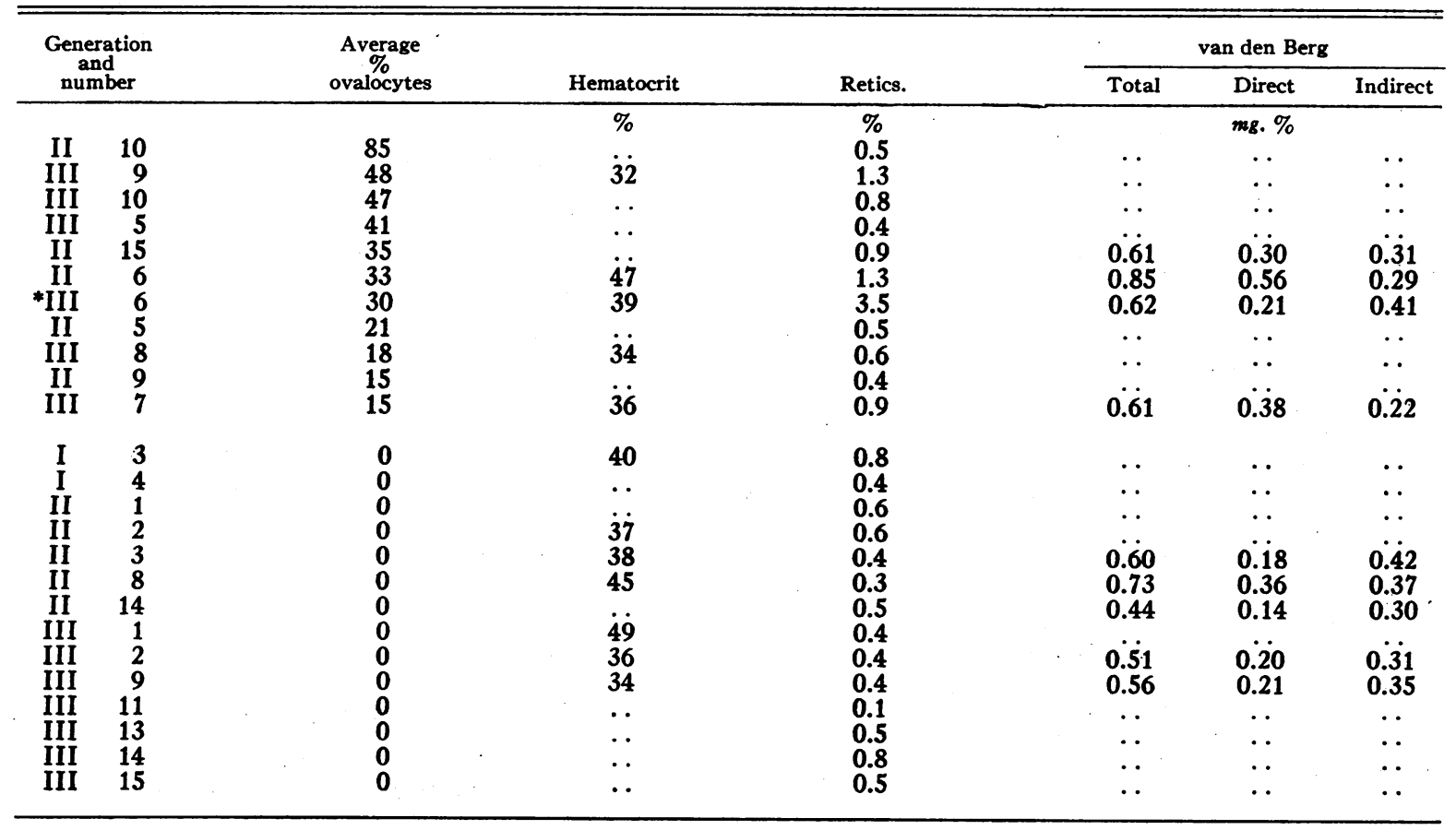

* Proposita. 